\title{
A concept of innovation hub for smart applications, enabling pro-active approach to urban policy and planning processes
}

\author{
Cezary Mazurek \\ Poznan Supercomputing and Networking Center \\ mazurek@man.poznan.pl
}

\author{
Maciej Stroinski \\ Poznan Supercomputing and Networking Center \\ stroins@man.poznan.pl
}

\begin{abstract}
In recent years, the question of how to develop smart applications in environments where solutions already exist has become a challenge for many trends of technological transformation e.g. in industry, transport or smart cities. The latter trend is additionally very sensitive because of the social dimension of the impact of transformation, where the human being should be in the centre of attention. In this paper we present the concept of the Innovation Hub in Poznan, which is a framework for digital transformation focused on integration and development towards proactive digital city system. Starting from the pillars of the digital transformation, i.e. the City Development Strategy and existing wellfunctioning smart city components, we justify the evolutionary model of transformation by creating favorable conditions for the implementation of Proof of Concept projects with the active participation of residents. In addition, we point out examples of projects that were linked to decision-making processes.
\end{abstract}

\section{Introduction}

For many years, intelligent and innovative infrastructure has been one of the critical resources determining the pace of society's development. Economic development, safety, transport and even health depend heavily on how local communities harness the latest scientific and technological advances as well as advanced infrastructure. Today, it even states that infrastructure plays a key role in all three dimensions of sustainable development: economy, environment and society. And now that the world is moving towards ambitious goals such as Sustainable Development Goals (set out in the Global Agenda 2030), New Urban Agenda and the Paris Agreement on climate change, infrastructure is increasingly recognized [1] [2].

In this context, the universal 'Smart City' concept, understood as a new generation of innovative services operating within and across key areas of life, takes on a broader meaning, especially in terms of its dynamic impact on decision-making processes. Key in this respect is support in the form of platforms and technologies that support integrated analysis of data from many sources, predictive models that capture the behavior of individual urban systems as well as the interdependencies with related systems, automated system controls and interactions, and capabilities for decision-makers at all levels - from individual residents to government officials, and from small businesses to large-scale service providers - to use these integrated data sources and models to inform their own interactions and decisions [3].

If we look at such a platform from the point of view of its functions integrating technology and service providers, their addressees and recipients, and decision makers, then together with such an environment we can treat it as a hub of innovation. It is the focal point of the local Smart City innovation ecosystem, but it is more than just hyper-connected technologies to progress [4].

In such an environment the development of technologies and smart applications takes place most often through the implementation of projects, that use the Proof of concept method to verify the usefulness of technologies or concepts of application scenarios. The availability of advanced cyber infrastructures, including modern IoT platforms, is an essential element in the implementation of such projects. Moreover, their implementation is placed in a real urban environment and their effects are more embedded in the life of the city, its inhabitants and its administration [5].

In this paper, we present the concept of the Innovation Hub in Poznań, which is a framework for digital transformation focused on integration and development towards proactive digital city system. Possession and conscious management of such an environment gives an opportunity for a close and proactive connection between the city development strategy, extensive components of smart cities and the digital transformation processes taking place with the active participation of residents. The model of such a transition, we applied in Poznan is targeting each of the three key dimensions of sustainable development: 
society, environment and economy. This new concept, which is a natural evolution of the ground floor described in [6], is being verified and improved through Proof of Concept projects presented for each of the above dimensions.

In chapter 2, we present the basis for building the digital transformation, which is the city development strategy. In chapter 3, we present the catalogue of existing Smart City components. Than, in Chapter 4, we introduce examples of three dimensions of sustainable city development: social, environmental and economic. In Chapter 5, we present the concept of transformation of existing resources and new tools to stimulate proactive management of the city space. Chapter 6 presents the conditions for future development and sustainability of the Innovation Hub model based on the existing Living Lab infrastructure.

\section{Digital transformation pillar - the City development strategy}

Poznań, with a population of 538 thousand (data from 2017), is the capital of the Wielkopolska region, an important academic center ( 8 universities, 33 research institutes), cultural center (4 theatres, opera house, philharmonic hall) and an important economic center with easy access to advanced IT infrastructure. Among the region's smart specializations, which are all strongly linked to modern technologies, are the following: ICTbased development, Modern medical technologies, Specialized logistics processes, Manufacturing industry of the future, Biomaterials and food and Interiors of the future [7].

Global development trends in relation to cities, as well as future vision of the city led to the formulation of the Development Strategy of the City of Poznan [8].

According to the outlined vision, thanks to the favorable business climate and the social cohesion policy, the city of Poznan will enable all its inhabitants to become fully involved in the life of the city. The above vision led to a very concrete mission of the city, which is to shape the conditions for the co-creation of the city by all the inhabitants.

The Development Strategy of the City of Poznan is based on five priorities, for which specific objectives have also been defined:

- O1: Strong Metropolis - develop the cohesion of the Poznań Metropolis and increase its role on the international arena through the development of institutional and economic links in regional, national and global networks,

- O2:Smart entrepreneurship - develop a diversified, strong and modern economy

- O3:Green, mobile city - make Poznań a 'green', eco-mobile city with green areas easily accessible to all and environmentally friendly sustainable transport,
- 04:Friendly, residential estates - provide residents with a high quality of life within housing estates with their own unique character,

- O5:Community and social dialogue - create new and develop existing mechanisms, forms of support and actions allowing the inhabitants to make responsible co-decision on the development of the city.

While addressing these individual priorities, the strategy also outlines strategic actions, many of which relate to technology, innovative application areas (verticals) as well as new collaboration models.

Technologies are presented as an important factor for innovation and improvement of quality of life. Among them there are references to computer networks, e.g.: Supporting the development of telecommunications broadband networks and services (e.g. cloud computing); virtual reality, e.g.: Creating a real and virtual space for international contacts for business, science and education, culture and sport; Big Data and IoT e.g.: Real-time integration of many multi-layer distributed digital data sources; green ICT, e.g.: Introducing modern, energy-saving technologies and solutions in public spaces and buildings; media and social networks: Building an efficient system of social dialogue and urban information using traditional media, modern technologies and social media.

Also innovative vertical areas are broadly addressed, e.g.: Supporting the development of solutions in the field of Industry 4.0; Introducing elements of innovation into the education system in Poznań schools; Supporting the growth of the game development sector.

And finally, there are also examples focused on new collaboration and co-creation models, e.g.: Creating conditions and encouraging the establishment of co-working spaces in the city, Building mechanisms of co-creation and renewal of public space with the participation of residents and private entities.

Moreover, it should be noted that most priorities are additionally associated with a decision-making loop at the city level by ensuring ubiquitous availability of intuitive urban e-services.

In this context, the Strategy provides a definition of Smart City as a new generation intelligent city using advanced ICTs and modern participatory management methods to improve the quality of life, based on the potential of social capital and involving residents in the process of building intelligent urban solutions.

The city's Strategy and digital transition program currently under preparation will allow implementing actions towards Smarter City in these strategic areas. The idea is to create favorable conditions for the transformation from today's smart city [6] to a smarter city. The digital transformation program should give a smarter city picture in strategic areas, and with the use of emerging and disruptive technologies. This approach can be implemented using the PoC model.

Page 6590 


\section{Existing Smart City components}

As outlined in [5], while various revolutionary solutions have been deployed to make the cities smarter, we believe that a more evolutionary path makes it easier for the cities to change into smart ecosystems. Such an evolutionary path was possible with the right foundation, that has been making the city of Poznań, Poland, smarter over the last 20 years, and opens opportunities for employing the Citizen Science model of smart city development. This foundation relates to the combination of the creation of a common data space, and the technological partnership with a research and development center and research cyberinfrastructure operator such as the Poznan Supercomputing and Networking Center (PSNC).

The result of cooperation between PSNC and City Hall is a growing array of Smart City landscape components, including infrastructure assets, open data platform and user-friendly applications.

\subsection{Infrastructure}

According to the main rationale for the concept presented in this paper, intelligent and innovative infrastructure is one of the critical resources determining the pace of society's development.

In the context of the partnership, the city of Poznan and the PSNC have both established the ICT infrastructure (cyber-infrastructure) that are critical for digital transformation of the city. Such infrastructure has been embedded in urban space. Their components most often have different characteristics such as technical, organizational (ownership and operator model) and variable level of innovation (readiness for digital transformation, openness and availability of data). For example, in Poznań, operators of technical infrastructure are private entities, but some of them are connected to the fiber-optic scientific network and therefore have easier and more secure access to data storage and analysis systems. CCTV system in the city is a system of cameras based on own optical fibers operated by the police. The data obtained from the cameras is stored for the period required by law. There is currently no access to this data outside of the authorized services. PEKA Poznan Agglomeration Electronic Card is a system managing electronic cards for the residents of Poznan, which is aimed at unifying the way of consuming transportation services delivered by different providers and enables to benefit from various services such as parking zone ticketing, library usage, sports, e-wallet, esignature and e-identification.

Therefore, the challenge remains to effectively and evolutionarily build sustainable solutions of smart applications and services in such a diverse environment, which will additionally provide synergy with different points of policy-making and planning processes, with the participation of citizens.

\subsection{Open Data Platform}

One of the possible approaches to tackle challenges on infrastructure convergence is data-centric integration. In a digital age, data is a key resource for social and commercial activities and much of data is created or held by government. By opening up data, government can help drive the creation of innovative business and services that deliver social and commercial value [9].

The City of Poznan supports the sharing of open public data and actively engages in developing solutions for smart urban space management. The city is a member of Open \& Agile Smart Cities [10] where it can exchange experiences and good practices in the field of using open data and building innovative solutions for the Smart City. Measures taken in this respect are to improve the management of the urban organism and bring benefits not only to city units, but also to external entities and residents.

In 2011, Poznań was the first city in Poland to publish a pilot set of application interfaces (APIs) to provide, among other things, selected subsets of spatial data, data on events in the city, on the MIM platform. The data sets were made available on the basis of the principles set out in the Act on Access to Public Information and similar to the conditions of the Creative Commons Attribution-Share Alike 3.0 license.

Some examples of open data platforms enable citizens to help municipalities locate and fix life issues that affect public wellbeing, such as full garbage bins, public lightening failures, road safety, dead animals, abandoned cars and many others [11] [12].

\subsection{Applications}

The data provided and the infrastructure allow us to develop applications, some of which (e.g. Atmosphere for Poznan) are connected to decision processes of the City Hall. Some applications are connected directly to information sources provided by external bodies (e.g. When I go - PEKA). The City of Poznań, together with PSNC, made a set of applications available to the residents.

Information on the forecasted and actual condition of air quality in Poznań (provided by Atmosphere for Poznań), is related to the applicable legal regulations in Poland - the detection of unfavorable conditions is automatically connected with the decision on free public transport, communicated in the application.

Other example, When I go - PEKA application, informs about the exact time of departure of the bus or tram. The data comes from the ITS system, installed e.g. in public transport vehicles or at bus stops, and is updated on an ongoing basis, taking into account the current traffic situation. 
Internet users can use also other city mobile applications and online services as well as commercial applications using open city data, such as FindPark, GPSwielkopolska, Nextbike, SmartZOO, and electronic job market.

Participants in major municipal events could use mobile applications dedicated to them. Work continued on the launch of the innovative OtwartyPoznan.pl website (a project launched in February 2018), which is an interactive platform for social participation.

\section{Key dimensions for sustainable development goals}

The prognosis of city development (and society and economy more broadly) by 2030 must be based on the Digital Age paradigm, i.e. ensuring harmonious digital cooperation within the entire urban ecosystem [13]. This requires the development of a proper digital transformation strategy, taking into account the already existing "smart city" environments, as well as creating conditions for harmonious integration of future solutions and applications (proactive composition and orchestration).

Therefore, we plan to consider the three main areas of influence of Sustainable Development Goals according to the following concepts:

- $\quad$ social as Human Centric Development

- environment as Climate-neutral city

- $\quad$ economy as Digital Transformation of Industry and Entrepreneurship

Each of the three above concepts fits into the specific objectives of the City Development Strategy, presented in chapter 2. And so: Human Centric Development supports the implementation of $\mathrm{O} 4$ and $\mathrm{O} 5$ objectives, Climate-neutral city refers especially to $\mathrm{O} 3$ and $\mathrm{O} 4$, and Digital Transformation of Industry supports $\mathrm{O} 1$ and $\mathrm{O} 2$ objectives.

The dimension of each of these areas will be presented below.

\subsection{Society: Human centric development}

The cities most affected by the problems also offer "natural conditions for cooperation to solve social challenges" [14].

The crucial thing here is to make the potential of technology and infrastructure available to a critical mass of actors, which in the case of cities is a natural but also a diverse ecosystem of residents. Digitalization of the city towards Smart City is a great social and economic challenge, so success is possible only with active involvement of the inhabitants in these processes. Therefore, the participation of residents in research, creation of a "proof of concept", verification of new solutions and implementations is mandatory.
The instruments that are used to implement this participation are Living Laboratories.

An illustrative case of the importance of Living Laboratories for increased participation in the context of Poznań was referenced in [15]. On a continuous basis PSNC's Future Lab animates communities in areas such as: technology-oriented user groups, medical white staff, carers of the elderly and disabled, educators. To secure user retention and keep access to representatives in a variety of application areas, Future Lab attracts users by organizing events and competitions - annually more than 100 events with $1000+$ participants. Event participants are potential panelists for use case testing. For every ICT application environment a new panel of users is being constructed and animated accordingly to identified usage environments and solution features. Panel scale ranges from 5-50 users depending mainly on the expected level of users' expertise and uniqueness. Panel duration is normally limited by the duration of R\&D activities (1-3 years), although preserving the panel for beta testing is a good practice and can massively support the sustainability of the product/service in question. Involvement of municipality is prerequisite for the implementation phase in the majority of social innovations.

The example of latest activities focused on humancentric developments is WINS project [16]. Its goal has been to identify 30 local social innovators in the Wielkopolska region and establish 30 small-scale innovation projects in the field of care services for vulnerable persons: elderly and persons with disabilities. The AAL living lab environment has helped us provide adequate support to those innovators throughout the whole incubations process, starting with identification of the actual needs of the vulnerable persons concerning missing care services, through codesign of innovations with their direct participation, to field testing and evaluating of the developed solutions. The city of Poznań has enabled various types of facilities for the co-design and test activities. These included, among others, nursing homes or street infrastructure.

The city's policy is aimed at greater involvement of the residents in the shaping of this trend. Examples include a participatory budget and a system for reporting necessary interventions of the city's services (e.g. garbage, air pollution). Moreover, the courses of this activity are also aimed at increasing the participation of residents in events, which in particular are a cultural showcase of the city (e.g. broadcasting concerts of the H.Wieniawski violin competition, online co-production of opera performances). The involvement of the PSNC in these events will continue, and especially the new generation of associated services will address human-centric challenges. 


\subsection{Environment: Climate-neutral city}

The Paris Agreement, which was mentioned at the beginning of this paper, aims to ensure global climate neutrality in the second half of this century. However, this is not a task that can only be set before governments and administrations. For this reason, the United Nations Climate Change Organization launched the Climate Neutral Now initiative in 2015 to involve companies, organizations, governments and citizens in efforts to achieve climate neutrality.

Furthermore, one of the key mission areas of Horizon Europe program directly addresses these challenges, namely the Climate-neutral and Smart Cities mission [17]

The city of Poznan is already active in this area. An example of this activity is the Atmosphere for Poznan application, which we mentioned in chapter 3.3 and the mechanisms and instrumentation of this service were presented in [6]. This application is designed for residents. Moreover, the city develops and promotes ecological means of communication by bicycles or scooters.

However, expecting the city to be even more smarter in this area (e.g. in the urban planning process) requires the use of computational simulation technologies. PSNC has experience and all the necessary tools in this field, which created favorable conditions for defining $\mathrm{PoC}$ projects.

In this context, we have been developing modules of Air Quality and City Heat Island simulation in PSNC for several years to perform forecasts and analyses for various spatial scales - from the territory of the whole country, through the voivodeship, city, districts, to individual streets. Using tools for modeling and simulation, a concept was developed and prototype results of simulation modeling were presented, which were received by the Voivodeship Inspectorate of Environmental Protection in Poznan in the following areas:

- determination of the representativeness of metering stations,

- assessment and forecasting of air quality in the city, district, street canyon, with particular emphasis on Garbary Street in Poznań (substances: NO2, NOx, $\mathrm{SO} 2, \mathrm{PM} 2,5, \mathrm{PM} 10$ )

- location of measurement stations in a street canyon, with particular emphasis on Garbary Street in Poznań,

- determination of emission sources.

This activity is currently focused on two main problems: Weak circulation and air mass exchange as well as heavy urban traffic.

The problem of air circulation was addressed by providing forecasting of pollutant concentrations at different levels (Fig. 1) together with information for residents as well as modeling and simulation to remove or reduce pollutant (e.g.: traffic reorganization, new green areas).

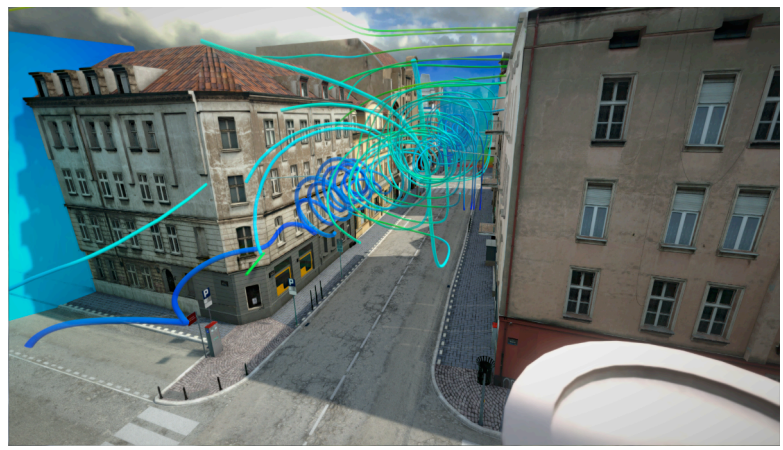

Figure 1. Visualization of air flow and concentration of NO2 in street canyon

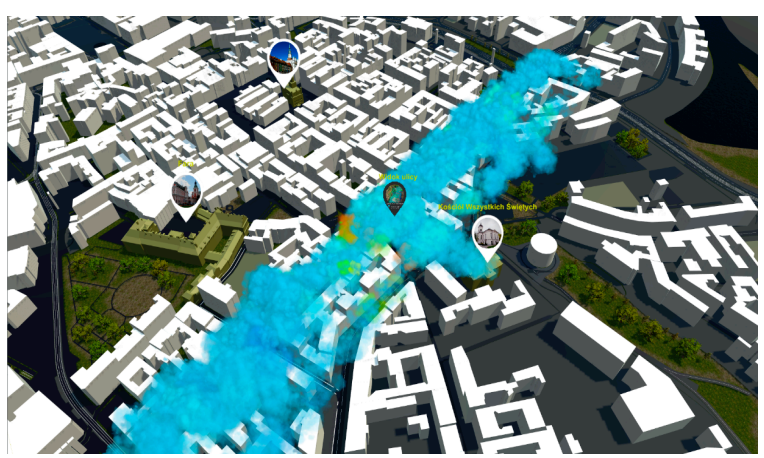

Figure 2. Impact of traffic on NO2 concentration in air

The second scenario, focused on streets with heavy traffic was addressed by the solution (Fig. 2), which offered:

- Information to citizens forecasting the impact of car traffic on air quality

- Modeling for reorganization of traffic

- Traffic control to minimize contamination

- Planning of new communication arteries

The main source of data used for modeling, simulating and visualizing selected urban spaces are the city's information resources (including the Spatial Information System, 3D model of Poznań), defined in the regulation of the Mayor of Poznan as the City Open Data Platform. Moreover, information from public entities making their resources available in the open data model is used, e.g. air quality data from the Voivodeship Inspectorate of Environmental Protection in Poznań.

For a correct analysis of the impact of urban planning on the environment, the following data is necessary:

- 3D terrain model,

- 3D information about urban space (buildings shape and height, street layout, etc.),

- Terrain coverage, i.e. low/medium/dense buildings, green areas (conifers, deciduous, mixed, bushes, grasses), soil type, etc., 
- Emissions of point (e.g. industrial chimneys), linear (car traffic), surface pollution (e.g. heating of dwellings).

Additionally, more detailed data may be used, e.g. permeability of building walls, their thickness, type of soil and its current moisture level at various depths.

The above example of an area of digital transformation into a smarter city shows the directions in which the city explores these possibilities based on advanced computing infrastructure. The most significant part of this $\mathrm{PoC}$ was the adoption of multi-scale modeling. In the workflow developed by PSNC, the idea was to combine global models' forecasts with local weather simulations using EULAG - a numerical HPC solver offering a large spectrum of application fields, including urban flows [18]. Data obtained from mesoscale forecasts is put into separate numerical model suitable for predictions at local scale. Initial data with resolution of several kilometers is supplemented with topography data, which are much denser (horizontal resolution of the order of meters). It allows to simulate local weather with denser computational mesh, also in vertical direction. In addition to this, the simulation produces results with smaller time intervals compared to the mesoscale models. The scheme of this workflow is shown in Fig.3

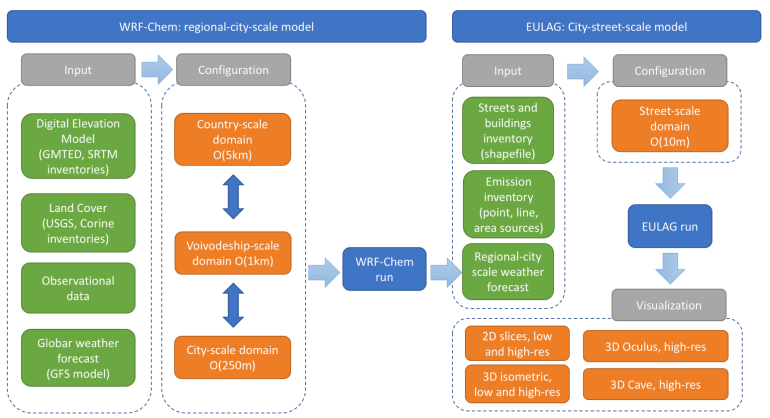

Figure 3. Computer simulation workflow

The deployment of this system for the city requires additional sensors and the work on such a concept was undertaken within an interdisciplinary team. The cost effectiveness was a barrier to this project, involving the installation of a significant number of sensors and an increased number of certified monitoring stations. The use of cheaper but non-certified stations, necessary with such a broad approach, although the validation and calibration algorithm had been developed, was not accepted by the decision-makers at the city level. Currently, the use of air quality sensors installed on school buildings is being considered as part of another nationwide project. Providing a data stream as a result will enable the deployment and practical use of the effects of the described PoC.

\subsection{Economy: Digital Transformation of Industry and entrepreneurship}

Cities are also increasingly perceived as hubs of entrepreneurial and innovative activity [19].

The city of Poznan is a member of the researchdriven cluster - ICT Wielkopolska and is active in promoting the development of industry and entrepreneurship in accordance with regional smart specializations. These are activities in which PSNC participates as well, adding its own solutions and competences..

As part of PSNC activities, including the urban coworking space and Living-lab [20] the HPC4Poland digital innovation hub was launched in 2016.

The mission of HPC4Poland is to guarantee local entrepreneurs access to the latest technologies and scientific achievements and to constantly aim at optimizing the conditions for creating innovations based on information technologies, while at the same time creating feedback in the form of practical perspectives for the scientific community and public participation. The main goal of the Hub is to increase the availability of computational services for Polish entrepreneurs, including digital simulations with advanced visualization and Big Data analysis. PSNC, as a center of competence of the HPC4Poland Digital Innovation $\mathrm{Hub}$, provides services based on its computing resources, laboratories and HPC expertise for the needs of creating and providing innovative services for enterprises. In this respect, it is important to cooperate with science. The node aggregates, for example, the competences of the Poznan University of Technology teams in robotics, artificial intelligence and intralogistics.

This activity is part of the digital industrial transformation trend known as Industry 4.0 and is in line with a renewed EU Industrial Policy Strategy "Investing in smart, innovative and sustainable Industry" [21]. It facilitates the deployment of breakthrough smart technologies in areas such as robotics, the Internet of Things, artificial intelligence, energy systems, strengthening the region's potential in line with smart specialization. Targeting its offer in particular at high-growth scale-up and start-up companies the Hub will provide them with access to advanced infrastructure and contacts with qualified people, technology centers and support organizations in the region. The Hub also strengthens people and businesses to improve their skills and adapt to social, economic and environmental change, e.g. by exploiting challenges in new employment models for innovators, based on urban innovation hubs and living laboratories with challenge driven coworking space.

\section{Towards pro-active approach in urban planning}

\subsection{The role of transformation partners}

Page 6594 
The concept of transformation of what is already there and new tools for pro-active management of the city space requires all actors to take up challenges in the scope necessary to develop a model of cooperation, which we can define as Innovation Hub. In the process of digital transformation of the city, especially in relation to decision-making processes, such a concept creates the best conditions for evolutionary development inspired by Proof of Concept projects. Based on the experience gained so far with the implementation of such projects, we can already formulate major challenges in relation to the participants of these projects:

\section{- For Business partners}

- Openness for cooperation in building data and software ecosystem

- Selection of data sets taking into account different levels of accessibility

- For Governmental institutions

- Transformation from Development Strategy, through Smart City Strategy into Open Data Strategy (data publication and stimulating data use)

\section{- For Scientific Leaders}

- Transformation from open data models, through automated data linking and discovery, to models of unified Big Data processing platform

\section{- For Citizens}

- Active participation in Smart City virtual community

- Developing new applications and providing data

- Activity in the living lab space

- For All

- Ensuring methods of security, reliability and privacy

Examples of taking up the above challenges in PoC projects will be presented in the next part of this chapter.

\subsection{Example 1 - Traffic analysis}

Experimental projects in the field of data analysis have been implemented in PSNC for a long time [22][23][24]. On the one hand, these are works connected with statistical analysis of various big data sets and the use of modern technologies of machine learning and artificial intelligence [25]. On the other hand, these works are aimed at using PSNC computational resources to implement scenarios based on big data technologies [26].

Statistical analysis together with data visualization was also carried out on data from the Poznan City Hall and related to information related to the use of WiFi urban network, urban bike infrastructure and selected Internet services. The data concerning voting on the civic budget and the school enrolment system were also analyzed.

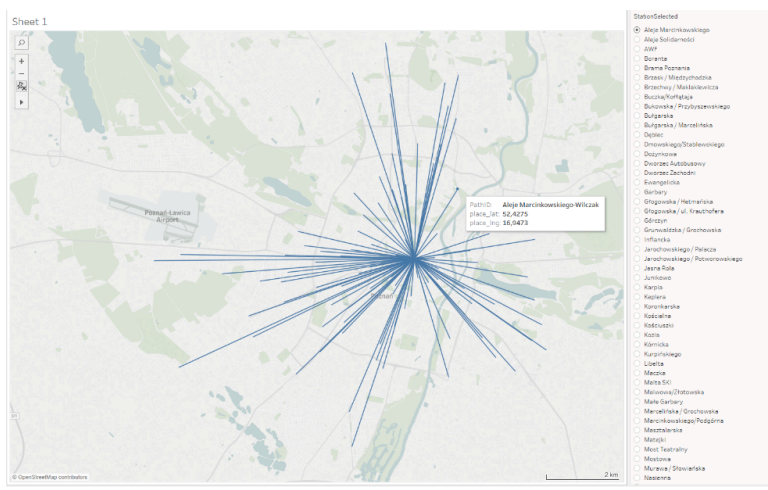

Figure 4. Visualization of the most frequently selected routes by bike users

One of these examples is the presentation of quantitative statistics on the use of the urban bicycle system. In order to improve the decision-making processes that the city was interested in, the following exemplary analyses were required in this respect:

- Carrying out quantitative analyses of the load of individual stations of a city bike

- Carrying out quantitative analyses of the variability of the use of the city bike system in the period of year / month / week

- Visualizations of the most frequently selected routes by users (Fig.4)

- Optimization of the number of bikes at individual stations, during major sports and cultural events in the city.

\subsection{Example 2 - Urban planning with virtual reality}

Modern urban management methods relies on the analysis of data collected from a variety of sources [27]. The multiplicity of these sources and the amount of information they provide require the use of specialized analytical mechanisms to extract key knowledge that is embedded indirectly in these data streams. To this end, we started working on the creation of the Digital Platform for Co-creation of Urban Spaces by developing (together with the City of Poznań) data acquisition mechanisms (primarily from information systems operating within the City Hall of Poznań and its subsidiaries), developing analytical tools supporting big data analyses and a set of simulation tools, supporting planning and design of urban space and visualization of the results of these analyses, as well as supporting the process of consultation and design of urban spaces with residents for new, innovative solutions based on ICT.

The project facilitates the preparation of immersive visualizations of various variants of new urban planning systems based on collected data and simulation results. The visualization through virtual reality devices allow the observer to fully perceive and understand the assumptions of the newly planned 
investments. The project is implemented with the use of advanced 3D visualization infrastructure CAVE type, which is available in PSNC (Fig. 5).

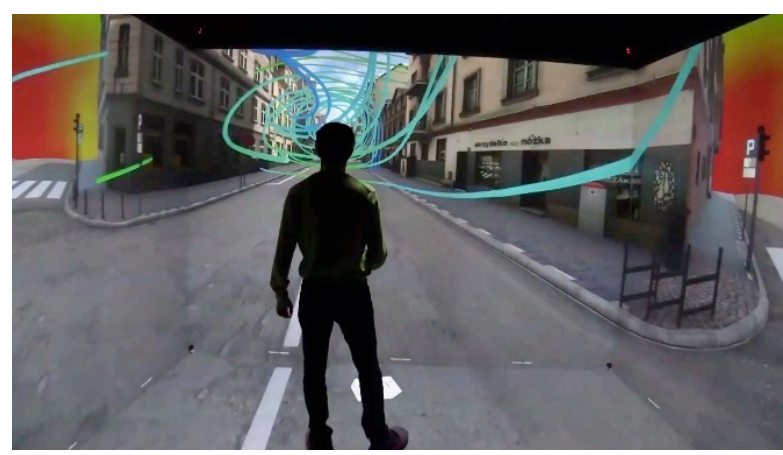

Figure 5. Urban planning 3D visualization in CAVE

\subsection{IoT platform integration}

The current state of the subject presented above as well as future developments clearly define that we are dealing with a heterogeneous environment in which it is necessary to integrate IoT platforms.

PSNC is involved in numerous projects related to the development and implementation of solutions of Internet of Things (IoT), providing products and knowledge in the field of design, creation of prototypes and ready-touse solutions at the level of hardware and software. The IoT integration platform, launched in Poznań, will provide communication between various, uniquely identifiable devices, sensors using the Internet for this purpose. In the context of smart cities, this means that all elements of urban infrastructure can be seen as nodes of the urban Internet of Things. The data generated by the nodes can be used by autonomous systems, but should be seen as an information resource co-creating the City Data Platform.

The comprehensive approach in this case assumes that the Innovation Hub creates conditions for experimenting with the development of applications (with the participation of residents but also in the model of the proprietary business solutions) based on a shared data space.

A separate layer is an area of security and privacy, often providing mechanisms of integrated access to data storage and processing services.

The diagram in the Figure 6 shows the three most important properties of this approach:

- In the IoT/Sensor layer, dynamic processing mechanisms are needed to perform data reduction, ordering, filtering, compression;

- Autonomous components of the Data Space can communicate with different sensor systems and adequately to their application workflows provide aggregation from multiple data sources.

- Two application models are allowed: those that use (possibly via Security and Identity Management mechanisms) the data layer and those that are closed solutions when applications are directly communicating with autonomous sensors.

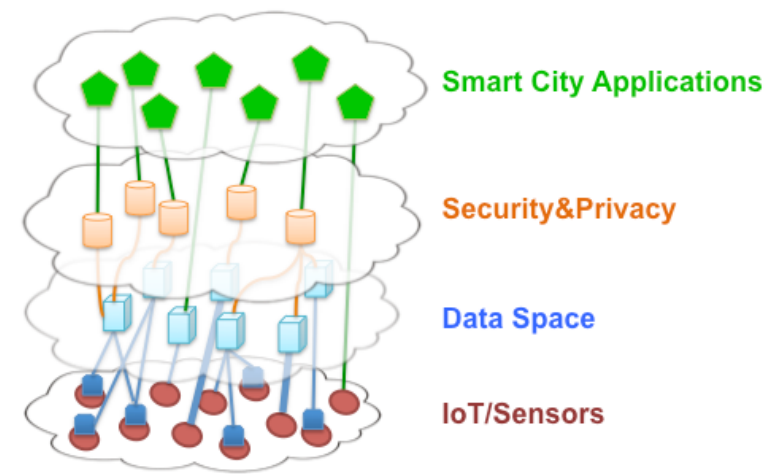

Figure 6. Accessing loT integration platform

The integration platform prototype is currently being developed based on OpenIoT [28] and Symbiote platforms. The main goal of SymbIoTe is to foster a simplified IoT application and service development process over interworking IoT platforms. [29]

\section{Impact and sustainability}

Coming back now to the issue of the feedback that the development of smart city applications can trigger in relation to cyber infrastructure, it is worthwhile to refer to the direction of these changes.

The starting point for the implementation of advanced computational scenarios was an analytical platform offered in PSNC, which is designed to collect, process and visualize large volumes of data based on tools dedicated to big data analysis. This environment is based on the ecosystem of open source software Apache Hadoop, which is a set of tools designed and built to process large amounts of data, supporting both serial and streaming or continuous data processing models.

However, high volumes of data require intensive processing on a large scale and in real time. Available cloud services are not able to meet the requirements for expected scalability and data storage and processing models. Whereas, high-performance computing environments are focused on central processing of locally stored data, new end-to-end data processing models are needed to ensure:

- Aggregation and pre-processing on edge devices (Edge Processing)

- Access to high-performance computing systems for analysis, simulation and knowledge discovery (using Machine Learning methods)

- A unified development and processing workflow enabling automatic inclusion of new data sources and application development.

These challenges are already perceived as a paradigm shift in computing [30]. In this context the 
Innovation Hub is becoming an environment for the development of smart applications in which digital transformation is a natural evolutionary process. One of the key issues, however, is the sustainability of such a model.

The problem of sustainability should be considered in the context of the proposed model of transformation into an integrated, proactive digital city system. We started from the strategy and developed smart city components that already exist. This is a good environment to ensure the process of digital transformation. What we needed for sustainable development was a combination of "platforms route" with a "beta route" approach [31]: Platform route, where cities focus on building the technology infrastructure to deliver a wide range of potential smart applications and services and Beta route where cities prioritize hands-on experience and launch multiple pilots to see how they perform without immediate concern for long-term deployment.

The above model also affects the sustainability and quality of software developed at the PoC stage. Best practices of software quality management applied by us in other works [32][33] are in this case transferred to PoC projects, which are usually shorter than typical software projects while keeping agile methodologies. However, maintaining the quality of the software development process in the $\mathrm{PoC}$ paradigm guarantees smooth use of software artifacts in the deployment phase [34]. This allows to avoid a frequent situation, when pilot projects or prototypes implemented in the R\&D\&I area, encounter barriers related to scalability, security or change management in software, at entering the stage of product development.

The model proposed by us is based on including in the process of PoC projects realization, the physical coworking space and Demo Space in PSNC's Future Lab. This is a place where we ensure cooperation of innovators, residents and city administration in the field of deployment of smart applications, their further development as well as new PoC projects identification.

In co-working space we are currently animating 16 user communities, gathered around information and communication technologies and around their application areas (e.g.: Java, Erlang, Adobe, PHP, Android, Angular JS). So far coworking gave birth to over 10 IT startups. It successfully runs acceleration batches, city challenge workshops, hackathons and living lab programs. These activities initiated the organization of similar events in several other places in the city, and their core part was often the use of an open API for city data.

Demo Space is a place for consulting and collecting opinions on the results of $\mathrm{PoC}$ projects. This space also guarantees the sustainability of the results by launching the process of transfer to operational deployment. After all, it is a place to which we plan to attract financing offers for further projects and research in the future.

\section{Conclusions}

Cities are key centers significantly influencing the pace and directions of human development. For this reason, the digital transformation of cities plays a key role in creating social and technological innovations that define the quality of life of future generations..

In this paper we presented the concept of the Innovation Hub in Poznań, which is a framework for digital transformation focused on integration and development towards proactive digital city system.

We have adopted an evolutionary model because different urban environments are not entirely ready to adopt new solutions and to change the existing models of city functioning. Moreover, existing systems with established functionality need to be continued. The simplest solution when we think about integration is an approach based on technological challenges, while we are convinced that we should look at this problem from the perspective of human-centric and new economydriven challenges.

We are still not aware of the importance of urban processes (multifaceted) in the context of the importance of big data and artificial intelligence analyses and the impact they will have on the future development of cities in a global perspective. However, we are convinced that in the context of these challenges, an increase in the quality of life will be a natural factor verifying the processes of urban evolution. The Innovation Hub environment proposed in this paper helps understand the conditions that influence the pace of digital transformation through the implementation of $\mathrm{PoC}$ projects and their results.

\section{References}

[1] Economist Intelligence Unit, "The critical role of infrastructure for the Sustainable Development Goals", 2019, https://content.unops.org/publications/The-critical-role-ofinfrastructure-for-the-SDGs_EN.pdf, Accessed on 20190606

[2] New Urban Agenda, United Nations Conference on Housing and Sustainable Urban Development (Habitat III) in Quito, Ecuador, on 20 October 2016, United Nations, 2017, http://habitat3.org/wp-content/uploads/NUA-English.pdf, Accessed on 20190606

[3] Nahrstedt K., Cassandras C., \& Catlett C., "City-Scale Intelligent Systems and Platforms". arXiv preprint arXiv:1705.01990 (2017)

[4] Goryachev A., "Creating an environment of coinnovation is the key to smart cities", Smart Cities Dive, July 24, 2018, https://www.smartcitiesdive.com/news/creating-anenvironment-of-co-innovation-is-the-key-to-smart-cities/528493/

[5] Menouar H, Guvenc I, Akkaya K, Uluagac AS, Kadri A, Tuncer A. "UAV-enabled intelligent transportation systems for the smart city: Applications and challenges". IEEE Communications Magazine, vol. 55, no. 3, pp. 22-28, Mar. 2017.

[6] Mazurek C., Stroiński M. "Common data and technological partnership - the foundation for the development of smart cities - Poznań Case Study".

Page 6597 
Proceedings of the 52nd Hawaii International Conference on System Sciences (HICSS 2019), pp 7390-7398.

[7] "Smart Specialisation Platform" http://s3platform.jrc.ec.europa.eu/regions/PL41/tags/PL41

[8] Borkowski M., "Civil society needs and expectations: What does NGI do for the people?", The New Generation Internet Workshop, Poznań, 8.06.2017r

[9] “Open Government Data” https://opengovernmentdata.org/

[10] “Open and Agile Smart Cities" https://oascities.org

[11] Valentino S., "EU smart cities join the data boom", European Data Journalism Network, January 15, 2019 https://www.europeandatajournalism.eu/eng/News/Datanews/EU-smart-cities-join-the-data-boom, Accessed 20190606

[12] Valentino S., "We want to help cities to become interoperable" European Data Journalism Network, January 15, 2019, https://www.europeandatajournalism.eu/eng/ content/view/full/1988, Accessed on 20190606

[13] The age of digital interdependence. Report of the UN Secretary-General's High-level Panel on Digital Cooperation, 2019, https://www.un.org/en/pdfs/DigitalCooperation-reportfor\%20web.pdf, Accessed on 20190606

[14] Kulkki S., "Towards Human-Centric Socio-Economic Development", Interdisciplinary Studies Journal, Vol 3, N 4, Special issue, 2014.

[15] Citizen-Driven Innovation. A guidebook for city mayors and public administrators [Online] available at: https://openknowledge.worldbank.org/bitstream/handle/10986/ 21984/Citizen Driven Innovation Full.pdf?sequence= Accessed on 20190606

[16] http://www.inkubatorwins.pl/

[17] Orientations towards the first Strategic Plan implementing the research and innovation framework programme Horizon Europe, European Commission, 2019

https://ec.europa.eu/research/pdf/horizon-

europe/ec_rtd_orientations-towards-the-strategic-planning.pdf

[18] "EULAG Model." https://www2.mmm.ucar.edu/eulag.

[19] Belderbos, R., Du, S. and Somers, D. "Global Cities as Innovation Hubs: The Location of R\&D Investments by Multinational Firms." In DRUID Academy. Aalborg, Denmark, 2014, https://conference.druid.dk/acc_papers/rdv4by82h7nby ph96iuix18cu71s.pdf.

[20] Garcia Robles, Ana, et al. "Introducing enoll and its living lab community.", 2016, https://issuu.com/enoll/docs/enollprint? $=23453591 / 33195876$, Accessed on 20190606

[21] Investing in a smart, innovative and sustainable Industry. A renewed EU Industrial Policy Strategy, European Commission, COM(2017) 0479, https://eur-lex.europa.eu/legalcontent/en/TXT/?uri=CELEX\%3A52017DC0479, Accessed on 20190704

[22] Fiore, S., Plociennik, M., Doutriaux, C., Palazzo, C., Boutte, J., Zok, T., Elia, D., Owsiak, M., D’Anca, A., Shaheen, Z., et al. "Distributed and cloud-based multimodel analytics experiments on large volumes of climate change data in the earth system grid federation ecosystem". In: Big Data, 2016 IEEE International Conference on Big Data, pp. 2911-2918. IEEE (2016)

[23] Mazurek C., Mielnicki M., Nowak A., Stroiński M., Werla M., Węglarz J., "Architecture for aggregation, processing and provisioning of data from heterogeneous scientific information services". [In:] R. Bembenik, R. Skoneczny, H. Rybiński, M. Kryszkiewicz, M. Niezgódka (eds.), Intelligent Tools for Building a Scientific Information Platform: Advanced Architectures and Solutions. Springer 2013, pp. 529-546.

[24] Krystek M., Mazurek C., Palma R., Pukacki J., GomezPerez J.M., "Research Object as mechanism for ensuring research experiment reproducibility within virtual research environment", TASK Quarterly: scientific bulletin of Academic Computer Centre in Gdansk, 2017, Vol. 21, No 4, pp. 379-389, DOI:10.17466/tq2017/21.4/

[25] Wasilewicz, R., Wasilewicz, P., Czaplicka, E., Kociecki, J., Blaszczynski, J., Mazurek, C., Slowinski, R., 24 hour continuous ocular tonography Triggerfish and biorhythms of the cardiovascular system functional parameters in healthy and glaucoma populations. Acta Ophthalmologica, 91:0. doi: 10.1111/j.1755-3768.2013.2721.x

[26] "About DataBio: Technology" https://www.databio.eu/en/approach/

[27] The Role of AR and VR in Urban Planning, AR Post, January 10, 2019, https://arpost.co/2019/01/10/role-ar-vrurban-planning/, Accessed on 20190604

[28] “OpenIoT” http://www.openiot.eu/

[29] Carozzo G., "Initial steps to build a symbIoTe enabled App", SymbIoTe Blog, March 8, 2018

https://www.symbiote-h2020.eu/blog/2018/03/08/initialsteps-to-build-a-symbiote-enabled-app/

[30] Asch et al., "Big data and extreme-scale computing: Pathways to Convergence Toward a shaping strategy for a future software and data ecosystem for scientific inquiry". The International Journal of High Performance Computing Applications 2018, Vol. 32(4) 435-479

[31] Smart City Playbook, Machina Research (Gartner), November 8, 2016, https://machinaresearch.com/news/ machina-researchs-smart-city-playbook-examines-the-strategiesof-22-cities-as-they-become-smart-safe-and-sustainable/

[32] Laskowska A., Gorronogoitia Cruz J., Kędziora P., Lener I., Lewandowski B., Mazurek C., Di Penta M. "Best practices for validating research software prototypes MARKOS case study", eChallenges-2014, 2014, ISBN: 9781-905824-46-5

[33] Chojnacki J., Mazurek C., Walter B., Wolski M. "How Good Is My Project? Experiences from Projecting Software Quality Using a Reference Set" [In:] Kosiuczenko P., Zieliński Z (eds.) Engineering Software Systems: Research and Praxis, AISC, volume 830, Springer Nature Switzerland AG 2019

[34] Alowayyed, S. et al., "Patterns for high performance multiscale computing". Future Generation Computer Systems 2019, 91, 335-346.

Page 6598 